\title{
Ethylene Signaling Pathway and MAPK Cascades Are Required for AAL Toxin-Induced Programmed Cell Death
}

\author{
Keisuke Mase, ${ }^{1}$ Takahito Mizuno, ${ }^{1}$ Nobuaki Ishihama, ${ }^{1}$ Takayuki Fujii, ${ }^{1}$ Hitoshi Mori, ${ }^{2}$ Motoichiro Kodama, ${ }^{3}$ \\ and Hirofumi Yoshioka ${ }^{1}$
}

\begin{abstract}
${ }^{1}$ Laboratory of Defense in Plant-Pathogen Interactions, Graduate School of Bioagricultural Sciences, Nagoya University, Nagoya 464-8601, Japan; ${ }^{2}$ Developmental Regulation Laboratory, Graduate School of Bioagricultural Sciences, Nagoya University, Chikusa, Nagoya 464-8601, Japan; ${ }^{3}$ Laboratory of Plant Pathology, Faculty of Agriculture, Tottori University, 4-101 Koyama-Minami, Tottori 680-8553, Japan
\end{abstract}

Submitted 15 February 2012. Accepted 10 April 2012.

\begin{abstract}
Programmed cell death (PCD), known as hypersensitive response cell death, has an important role in plant defense response. The signaling pathway of PCD remains unknown. We employed AAL toxin and Nicotiana umbratica to analysis plant PCD. AAL toxin is a pathogenicity factor of the necrotrophic pathogen Alternaria alternata f. sp. lycopersici. $N$. umbratica is sensitive to AAL toxin, susceptible to pathogens, and effective in Tobacco rattle virus-based virus-induced gene silencing (VIGS). VIGS analyses indicated that AAL toxin-triggered cell death (ACD) is dependent upon the mitogen-activated protein (MAP) kinase kinase MEK2, which is upstream of both salicylic acidinduced protein kinase (SIPK) and wound-induced protein kinase (WIPK) responsible for ethylene (ET) synthesis. ET treatment of $M E K 2$-silenced $N$. umbratica re-established ACD. In SIPK- and WIPK-silenced N. umbratica, ACD was compromised and ET accumulation was not observed. However, in contrast to the case of $M E K 2$-silenced plants, ET treatment did not induce cell death in SIPK- and WIPK-silenced plants. This work showed that ET-dependent pathway and MAP kinase cascades are required in ACD. Our results suggested that MEK2-SIPK/WIPK cascades have roles in ET biosynthesis; however, SIPK and WIPK have other roles in ET signaling or another pathway leading to cell death by AAL toxin.
\end{abstract}

Programmed cell death (PCD) has important roles not only in the process of plant development but also in plant defense response, known as hypersensitive response (HR) cell death (Jones and Dangl 2006; Love et al. 2008). HR cell death is often initiated by a gene-for-gene interaction between a dominant plant resistance $(R)$ gene and a pathogen avirulence $(A v r)$ gene, which provides race-specific resistance that is easily overcome by pathogen mutations (Moffett 2009). Some pathogen-associated molecular patterns (PAMPs), such as INF1 elicitin (Kamoun et al. 2003), xylanase (Bailey et al. 1990), and AvrXa21 (Lee et al. 2009), also induce HR cell death. The HR cell death signaling pathway has been studied genetically and biochemically but the perspective of plant PCD is still unclear. Diverse biological processes are associated with a

Corresponding author: H. Yoshioka; E-mail: hyoshiok@agr.nagoya-u.ac.jp; Fax: +81 527894283

* The $\boldsymbol{e}$-Xtra logo stands for "electronic extra" and indicates that seven supplementary figures and two supplementary tables are published online. complicated network in the induction of HR cell death (Tsuda et al. 2009), suggesting that investigating the pathways and their components participating in plant PCD by the phenotype of HR cell death is difficult. For these reasons, we need to use a new cell death inducer to identify novel factors responsible for PCD.

Some pathogens produce phytotoxins that are pathogenicity factors and capable of inducing cell death in susceptible host plants (Markham and Hille 2001; Walton 1996). Hostselective toxins (HST), secreted by a range of fungal and bacterial pathogens, are signaling molecules that trigger PCD in plant cells, leading to host colonization and disease (Gilchrist 1998; Greenberg and Yao 2004). During the processes of plant PCD, morphologies sharing diagnostic markers of chromatin condensation and segregation into distinct masses referred to as pycnotic DNA bodies are observed (Levine et al. 1996; Sasabe et al. 2000; Wang et al. 1996). Victorin, an HST produced by Cochliobolus victoriae, induces cell death in oat cultivars carrying the dominant $V b$ allele (Wolpert et al. 1985). Victorin also induces cell death in Arabidopsis thaliana carrying LOVI encoding a coiledcoil nucleotide-binding site leucine-rich repeat, which has the molecular nature of many plant $R$ genes (Lorang et al. 2007). The process of victorin-induced cell death may share partially a common pathway with $R$ gene-mediated cell death. Indeed, victorin trigger plant defense responses (Tada et al. 2001). These studies suggest that victorin is a major pathogenicity factor in $C$. victoriae but functions as a defense inducer during the fungal infection process.

AAL toxin is an HST produced by Alternaria alternata $\mathrm{f}$. sp. lycopersici that causes disease in its natural host, tomato (Wang et al. 1996), and some Nicotiana spp. lacking the $\mathrm{Al}$ ternaria stem canker gene 1 (Asc-1) (Brandwagt et al. 2000, 2001). The $A s c-1$ gene is homologous to the yeast longevity assurance gene (LAGl) and has no homology to known plant $R$ genes. Sensitivity to AAL toxin is associated with the dysfunctional $A s c-1$ gene, and insensitivity presumably functions as a salvage pathway for ceramide-disrupted plant cells (Brandwagt et al. 2000). The sphingolipid ceramide is a key component of mammalian PCD (Taha et al. 2006), and also participates in plant PCD (Liang et al. 2003). Fumonisin B1 (FB1), which is a structural analogue of AAL toxin, is produced by Fusarium moniliforme (Gilchrist 1997). AAL toxin and FB1 are defined as sphinganine-analog mycotoxins (SAM), mycotoxin class (Fig. 1A). SAM structurally resemble sphinganine, an intermediate of sphingolipid biosynthesis (Wang et al. 1996). AAL toxin is a true pathogenicity factor of 
A. alternata $\mathrm{f}$. sp. lycopersici, because toxin-deficient natural variants or laboratory mutants cannot grow on living tomato plants (Akamatsu et al. 1997). FB1 production in F. moniliforme, however, is not required to infect maize ears (Desjardins and Plattner 2000). The baculovirus p35 protein directly binds to and inhibits caspases, which are cell death executioners, during baculovirus replication in insect host cells. Overexpression of p35 in transgenic tomato plants and treatment with caspase inhibitors block AAL toxin-triggered cell death (ACD) and confer resistance to a wide range of pathogens, including both fungi and bacteria (Lincoln et al. 2002). These studies indicate the possibility that HR cell death and phytotoxin-induced cell death share a common signal pathway. That is, AAL toxin appears to hijack the plant immune system to induce cell death and subsequent successful infection. FB1 induces PCD in wild-type Arabidopsis. Lesions formed on Arabidopsis in response to FB1 and HR by avirulent pathogens show striking similarities (Stone et al. 2000), which include accumulation of reactive oxygen species (ROS), deposition of phenolic compounds and callose, production of camalexin, and induction of defense-related genes. Thus, SAM possibly could be used as chemical cell death inducers to investigate the signaling network of plant PCD.

Nicotiana umbratica is sensitive to AAL toxin and is susceptible to A. alternata f. sp. lycopersici (Brandwagt et al. 2001). In this study, we developed a model system using AAL toxin and N. umbratica to investigate the PCD signaling pathway by using virus-induced gene silencing (VIGS). By using loss-of-functional analysis, we show that the ethylene (ET)mediated signaling pathway and mitogen-activated protein kinase (MAPK) cascade are required for AAL toxin-dependent PCD.
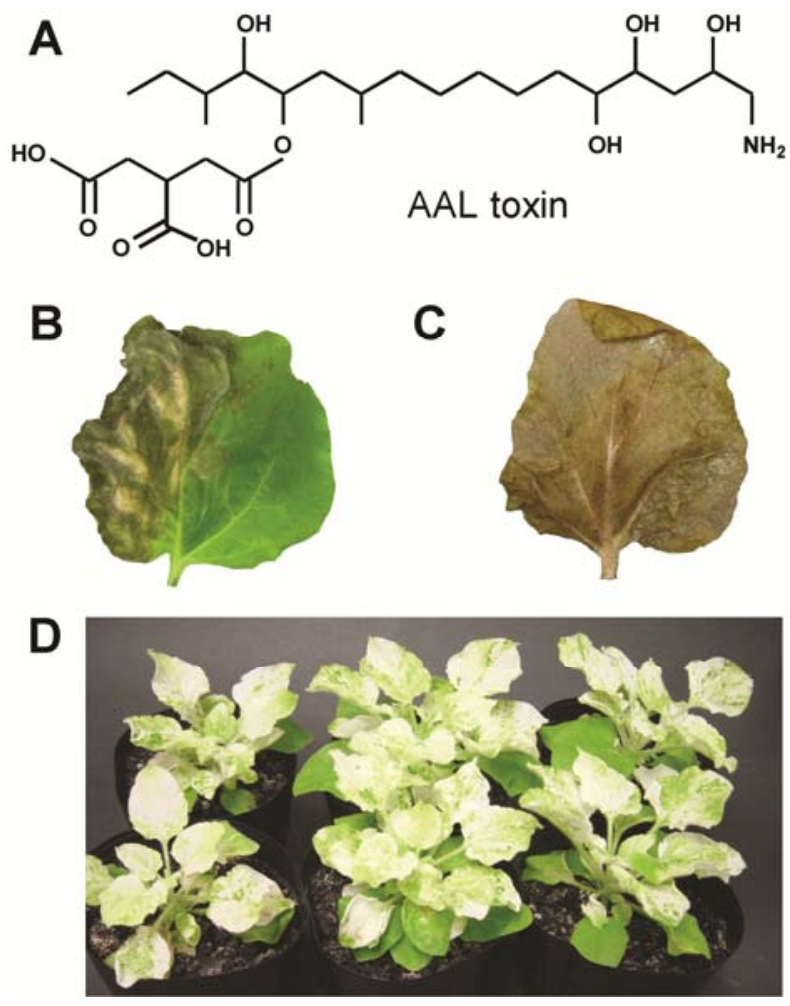

Fig. 1. The asc/asc genotype of Nicotiana umbratica is a model plant to investigate AAL toxin-triggered cell death. A, Structure of AAL toxin. B, AAL toxin-induced programmed cell death 3 days after treatment. C, Alternaria alternata f. sp. lycopersici caused necrotic symptoms 6 days after inoculation. D, Phytoene desaturase gene knocked down by virusinduced gene silencing.

\section{RESULTS}

\section{N. umbratica is a powerful tool to analyze plant PCD.}

The asc/asc genotypes of tomato and N. umbratica are sensitive to SAM and hosts of the AAL toxin-producing fungus A. alternata f. sp. lycopersici (Brandwagt et al. 2001). Therefore, we isolated the asc/asc genotype from $N$. umbratica plants and confirmed that the leaves were sensitive to AAL toxin (Fig. 1B) and susceptible to A. alternata f. sp. lycopersici (Fig. 1C). The Asc/Asc genotype of N. umbratica was insensitive to AAL toxin and resistant to A. alternata f. sp. lycopersici (Supplementary Fig. S1). N. umbratica leaves were also transformable by Agrobacterium tumefaciens GV3101 and the transient gene-expression system (agroinfiltration) was available (Asai et al. 2010). We previously showed that Tobacco rattle virus (TRV)-based VIGS vector is available for N. umbratica (Asai et al. 2010). Phytoene desaturase-silenced leaves showed a photo-bleached phenotype (Fig. 1D). These results indicate that AAL toxin-sensitive $N$. umbratica offers a new model system to analyze plant PCD.

\section{Effects of $M E K 2, V P E$, and $R B O H A / B$ silencing on ACD and susceptibility \\ to Alternaria alternata f. sp. lycopersici.}

To investigate the signaling pathways of ACD, we silenced several components that participate in HR cell death. MEK2 is a component of the MAPK cascade, which is a common phosphorylation cascade in eukaryotes. A MAPK cascade minimally consists of a MAPK kinase kinase (MAPKKK)-MAPK kinase (MPAKK)-MAPK module linked in various ways to upstream receptors and downstream targets (Nakagami et al. 2005). Many studies have extensively characterized tobacco MAPK, woundinduced protein kinase (WIPK), and salicylic acid (SA)-induced protein kinase (SIPK). The MEK2-SIPK/WIPK pathway, which is a MAPKK-MAPK pathway, has a positive role in $R$ genemediated disease resistance (Ekengren et al. 2003) or PAMPinduced basal defense (Ishihama et al. 2011; Tanaka et al. 2009). Expression of $M E K 2^{\mathrm{DD}}$, a constitutively active mutant of MEK2, leads to HR-like cell death; defense gene expression; and generation of nitric oxide, ET, and ROS, such as the superoxide anion $\mathrm{O}_{2}^{-}$and hydrogen peroxide $\left(\mathrm{H}_{2} \mathrm{O}_{2}\right)$; all preceded by activation of endogenous WIPK and SIPK (Asai et al. 2008; Liu and Zhang 2004; Yang et al. 2001; Yoshioka et al. 2003). Vacuolar processing enzyme (VPE) participates in $N$ gene-mediated and FB1-induced PCD (Hatsugai et al. 2004; Kuroyanagi et al. 2005). VPE is thought of as cell death executors in plants and has the activity of caspases, which is an animal cell death executor (Hatsugai et al. 2006). Respiratory burst oxidase homolog $(\mathrm{RBOH})$ is NADPH oxidase in plants and is associated with ROS burst. $N b R B O H A / B$-silenced $N$. benthamiana plants show suppression of resistance to pathogens and a reduced ROS burst (Asai et al. 2008; Yoshioka et al. 2003). We knocked down the genes $M E K 2, V P E$, and $R B O H A / B$ by using VIGS (Fig. 2A). The silencing effects on TRV:MEK2, TRV:VPE, and TRV: $\mathrm{RBOHA} / \mathrm{B}$ leaves were confirmed by comparing the expression levels with TRV control leaves (Fig. 2B). In N. benthamiana, $N b V P E 1 a$ and NbVPE1b are isolated (Hatsugai et al. 2004). We used the overwrapped sequence of VPEIa and VPE1b genes for a silencing construct to knock down both genes in $N$. umbratica (Supplementary Fig. S2). The half leaves were infiltrated with AAL toxin (Fig. 2A, upper). A necrotic region induced by AAL toxin was observed in TRV control and $R B O H A / B$-silenced leaves of $N$. umbratica at 3 days after treatment, whereas silencing $M E K 2$ or $V P E$ compromised ACD. To examine the pathogenicity of Alternaria alternata $\mathrm{f}$. sp. lycopersici on each gene-silenced $N$. umbratica, we inoculated the spores on to these leaves and observed disease symptoms from 6 days after 
inoculation (Fig. 2A, lower). The same was true for pathogeninduced necrotic regions in these silenced leaves.

To quantify cell death, we measured ion leakage of AAL toxin-treated leaves (Fig. 2C). AAL toxin-induced ion leakage was significantly suppressed in $M E K 2$ - and $V P E$-silenced leaves.

To further confirm the participation of MEK2 in ACD, we knocked down $M E K 2$ by using another fragment of $M E K 2$, named TRV:MEK2-2 (Supplementary Fig. S3A). To check the effects of $M E K 2$ silencing, we examined the expression levels of other MAPKK, MEK1, MKK1, and SIPKK in TRV, TRV: MEK2, and TRV:MEK2-2 plants (Asai et al 2008; Gomi et al. 2005; Takahashi et al. 2007). The mRNA levels of MAPK showed no noteworthy differences between TRV control leaves and $M E K 2$-silenced leaves, suggesting that silencing of $M E K 2$ did not affect the expression of at least three related $M A P K K$. To examine the efficiency of $M E K 2$ silencing, MEK2 ${ }^{\mathrm{DD}}$ was overexpressed in $M E K 2$-silenced and $M E K 2$-2-silenced leaves by agroinfiltration. Cell death and ion leakage were suppressed in TRV:MEK2 and TRV:MEK2-2 plants, suggesting that the function of MEK2 was suppressed in these MEK2-silenced leaves. ACD and AAL toxin-induced ion leakage were also suppressed in TRV:MEK2-2 plants. These results indicate that MEK2 participates in ACD.

Although differences in cell death phenotype between the TRV control and TRV:RBOHA/B were not observed (Fig. 2A), conductivity was slightly reduced in the $R B O H A / B$-silenced leaves, suggesting that ROS participate in ACD. To further evaluate the participation of RBOH-mediated ROS in ACD, we used diphenylene iodonium (DPI), an inhibitor of NADPH oxidase (Asai and Yoshioka 2009). ACD was induced in the presence or absence of DPI (Supplementary Fig. S4), indicating that $\mathrm{RBOH}$-mediated ROS do not have an important role in ACD in N. umbratica.

\section{ET-dependent signal pathway is especially required for ACD.}

SA-dependent and jasmonic acid (JA)- or ET-dependent signaling pathways are responsible for defense responses to biotrophic pathogens and necrotrophic pathogens, respectively (Glazebrook 2005). However, SA, JA, and ET signaling pathways appear to participate in FB1-induced cell death in Arabidopsis (Asai et al. 2000). AAL toxin induces PCD in tomato leaflets and protoplasts, and cell death in the leaflets induced by AAL toxin is suppressed by inhibitors of ET biosynthesis or perception (Moore et al. 1999; Moussatos et al. 1994; Wang et al. 1996). Exogenous SA or methyl jasmonate application does not influence disease symptoms of A. alternata f. sp. lycopersici on tomato (Egusa et al. 2009). To evaluate whether SA-, JA- or ET-dependent signaling pathways participate in ACD in N. umbratica, we silenced isochorismate synthase 1 (ICS1), coronatine insensitive 1 (COI1), and ethylene insensitive 2 (EIN2) by using VIGS (Fig. 3A). ISC1 is a key enzyme of SA biosynthesis (Wildermuth et al. 2001), COII is a signal component of JA

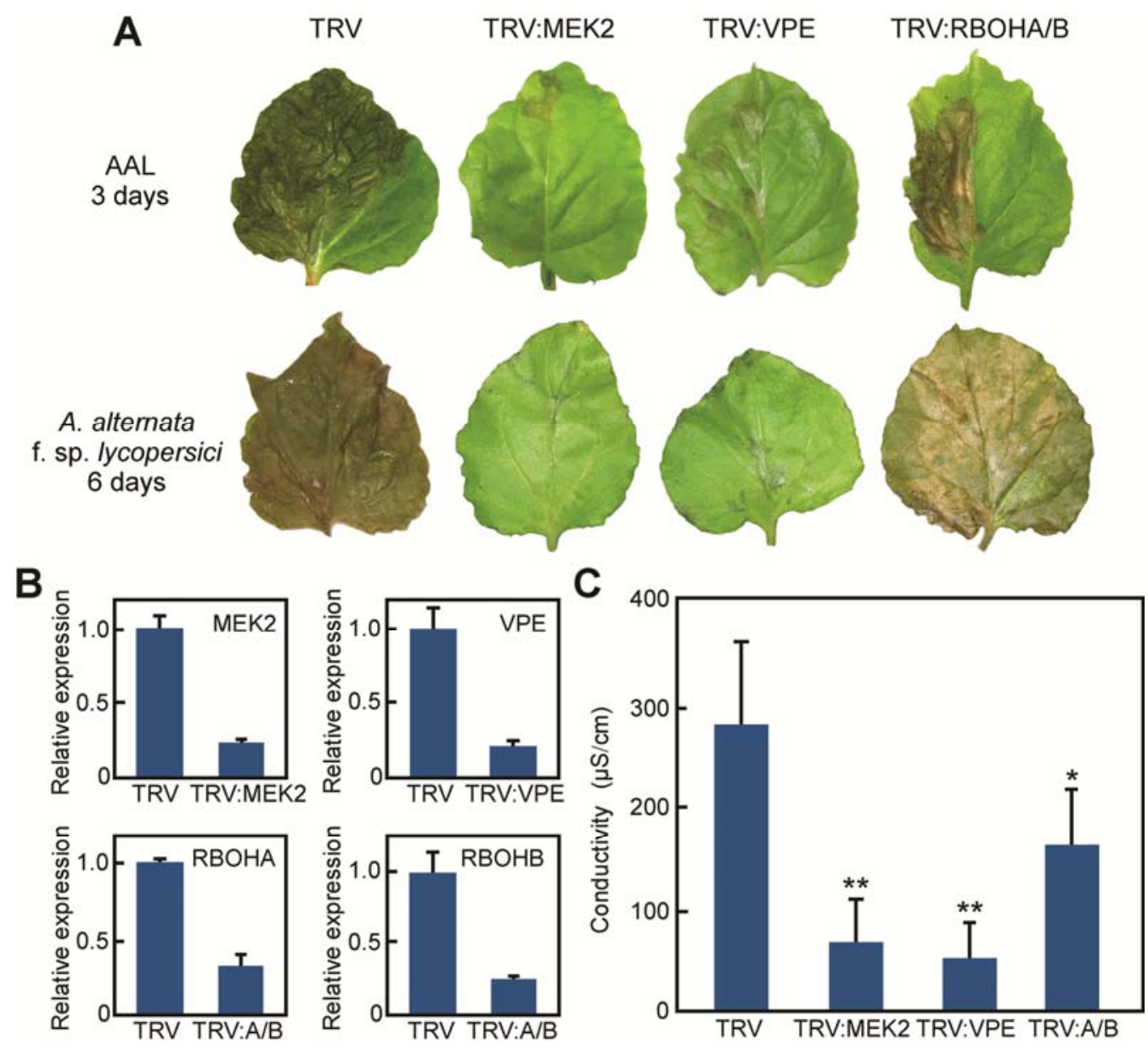

Fig. 2. Effects of silencing $M E K 2$, VPE, and RBOHA/B on AAL toxin-triggered cell death (ACD) and susceptibility to Alternaria alternata f. sp. lycopersici. A, Silencing MEK2 and VPE compromised ACD and disease symptoms caused by A. alternata f. sp. lycopersici. B, Silencing of target genes was confirmed by using quantitative reverse-transcriptase polymerase chain reaction. $E F-1 \alpha$ was used as an internal standard. Data are means \pm standard deviations (SD) from three experiments. C, ACD was quantified by ion leakage from AAL toxin-treated leaves. Data are means \pm SD from at least three independent experiments. Data underwent a Student's $t$ test: ** or * indicate $P<0.01$ or 0.05 , respectively, versus Tobacco rattle virus (TRV) control plants. 
(Xie et al. 1998), and EIN2 is an important component in ET signaling (Alonso et al. 1999). We knocked down EIN2, ICS1, and $C O I 1$ by using VIGS and confirmed the silencing effects by using quantitative reverse-transcriptase polymerase chain reaction (qRT-PCR) (Fig. 3B). ACD was compromised in EIN2silenced leaves but not in COI1- or ICSI-silenced leaves (Fig. 3A, upper). Disease symptoms caused by A. alternata f. sp. lycopersici were markedly reduced only in EIN2-silenced leaves (Fig. 3A, lower). We measured ion leakage of leaves treated with AAL toxin (Fig. 3C). The toxin-induced ion leakage was also reduced only in EIN2-silenced leaves. These results suggest that the ET-dependent signaling pathway is required for both ACD and pathogenicity of A. alternata $\mathrm{f}$. sp. lycopersici.

MEK2 participates in ET production (Liu and Zhang 2004), and EIN2 is an important component in ET signaling (Alonso et al. 1999). ACD was suppressed in MEK2- and EIN2-silenced plants, indicating that ET is a key regulator in ACD in N. umbratica. To confirm this possibility, we examined the effect of 1-methylcyclopropene (MCP) on ACD. MCP is thought to interact with ET receptors and, thereby, prevent ET-dependent responses (Watkins 2006). N. umbratica leaves were treated with AAL toxin in the presence or absence of MCP at $2 \mu \mathrm{g} / \mathrm{ml}$. At 3 days after treatment, cell death and marked ion leakage were observed only in MCP-untreated leaves (Fig. 3D and E), indicating that ET reception is an important process in ACD in N. umbratica. Thus, pharmacological studies and the results of VIGS indicated that ET has a pivotal role in ACD.

$M E K 2$ has a pivotal role in ET production in ACD.

We examined whether treatment of leaves with AAL toxin actually increases ET production in N. umbratica leaves. AAL toxin greatly increased ET production in TRV control leaves but not in MEK2-silenced leaves (Fig. 4A, left). These results suggest that suppression of ACD by VIGS of $M E K 2$ results from inhibition of ET production. Moreover, the amount of ET accumulation did not increase in the Asc/Asc genotype of $N$. umbratica by AAL toxin (Fig. 4A, right), suggesting that ET production depends on sensitivity to AAL toxin.

To further examine whether MEK2 has a role in ET production in the process of $\mathrm{ACD}$, we treated $M E K 2$-silenced plants with AAL toxin and ET at $10 \mu \mathrm{g} / \mathrm{ml}$. ACD was compromised in MEK2-silenced plants but recovered in the presence of ET with AAL toxin (Fig. 4B). We confirmed the conductivity of $M E K 2$-silenced leaves treated with AAL toxin or AAL toxin plus ET (Fig. 4C). Silencing MEK2 compromised toxininduced ion leakage but adding ET increased conductivity. These results indicate that $M E K 2$ has a pivotal role in ET production in ACD.

\section{SIPK and WIPK have multiple functions in ACD.}

In this study, we showed that $M E K 2$ participates in ET production induced by AAL toxin. Two crucial steps in the control of ET production are i) rate-limiting conversion of $S$-adenosylL-methionine to 1-aminocyclopropane-1-carboxylic acid (ACC) by ACC synthase (ACS) (Kende 1993), and ii) oxidative cleavage of ACC by ACC oxidase (ACO) to form ET, $\mathrm{CO}_{2}$, and cyanide (Adams and Yang 1979). SIPK is a downstream component of MEK2 (Yang et al. 2001) and participates in stabilization of ACS2/6 by direct phosphorylation (Liu and Zhang 2004). WIPK is a downstream component of MEK2 and its ortholog Arabidopsis MPK3 also participates in stabilizing ACS2/6 by phosphorylation of the same residues as
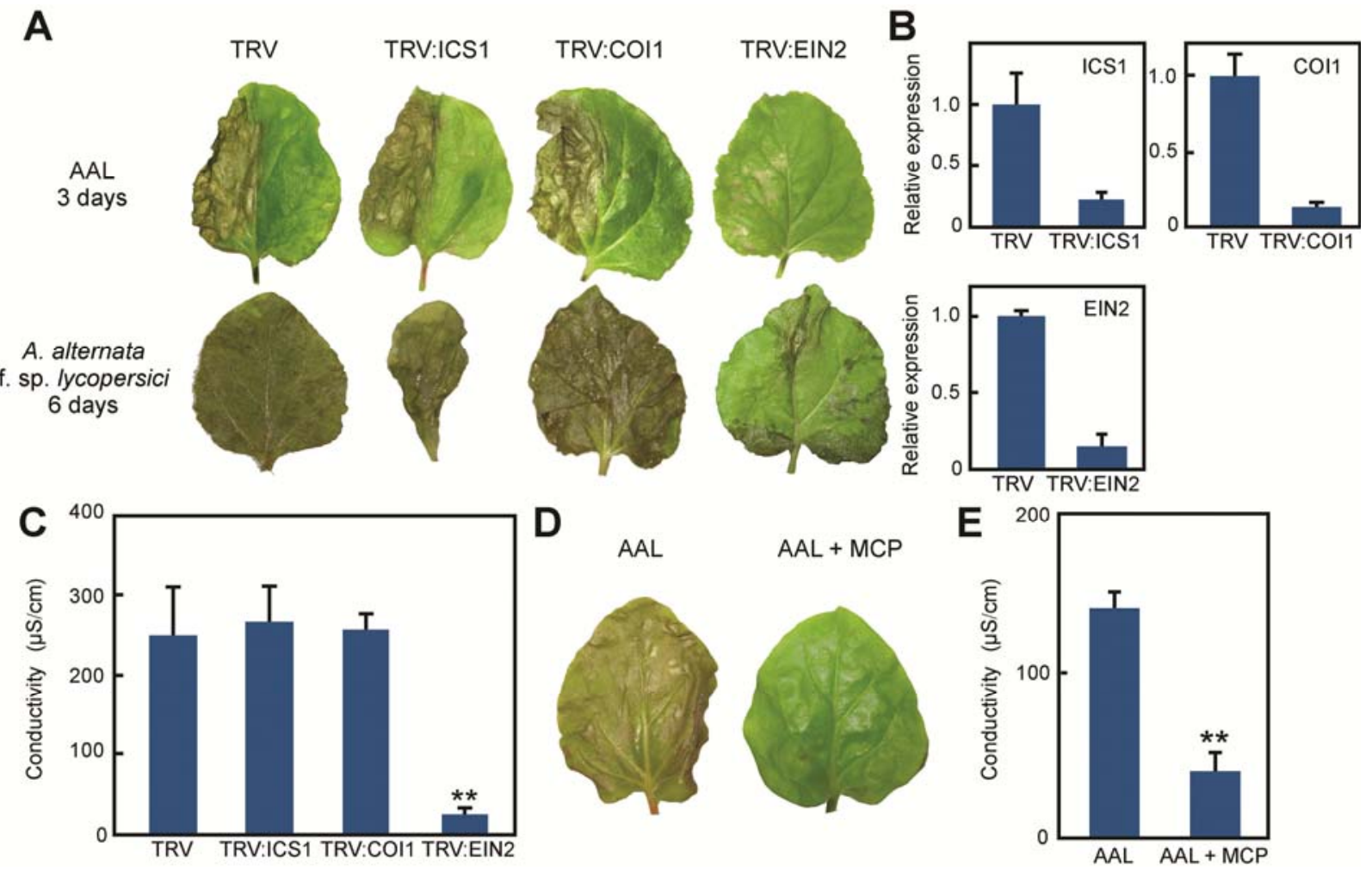

Fig. 3. Ethylene signaling is essential for AAL toxin-triggered cell death (ACD) and susceptibility to Alternaria alternata f. sp. lycopersici. A, Effects of silencing ICS1, COI1, and EIN2 on ACD and infection with A. alternata f. sp. lycopersici. B, Silencing of target genes was confirmed by using quantitative reverse-transcriptase polymerase chain reaction. $E F-1 \alpha$ was used as an internal standard. Data are means \pm standard deviations (SD) from three experiments. C, ACD was quantified by ion leakage from AAL toxin treated leaves. Data are means \pm SD from at least three independent experiments. Data underwent a Student's $t$ test: ** indicates $P<0.01$ versus Tobacco rattle virus (TRV) control plants. D, Effects of 1-methylcyclopropene (MCP) on ACD 3 days after treatments. Leaves were treated with AAL toxin in the presence or absence of MCP at $2 \mu \mathrm{g} / \mathrm{ml}$. E, ACD was quantified by ion leakage from AAL toxin-treated leaves. Data are means \pm SD from three experiments. Data underwent a Student's $t$ test: ** indicates $P<0.01$ versus AAL toxin treatment. 
MPK6 (Han et al. 2010; Kamiyoshihara et al. 2010). First, we examined whether SIPK and WIPK are activated by AAL toxin in $N$. umbratica by using immunocomplex (IC) kinase assay (Fig. 5A, upper). Activation of SIPK and WIPK was detected at 24 and $48 \mathrm{~h}$ after AAL toxin treatment but not water treatment, suggesting that MEK2-SIPK/WIPK cascade is activated by AAL toxin. In the Asc/Asc genotype of $N$. umbratica, SIPK and WIPK were not activated by AAL toxin (Fig. $5 \mathrm{~A}$, lower), suggesting that activation of SIPK and WIPK is dependent on the sensitivity of AAL toxin.

To confirm the silencing efficiency of SIPK and WIPK, we used agroinfiltration to overexpress $M E K 2^{\mathrm{DD}}$ in silenced leaves. Cell death and ion leakage were significantly suppressed by $S I P K$ - and WIPK-silenced leaves (Supplementary Fig. S5A and B), suggesting that SIPK and WIPK were effectively silenced. We also confirmed the knockdown of SIPK and WIPK by using qRT-PCR. We examined whether SIPK and WIPK participate in ET production during ACD. ET increased in TRV control leaves by AAL toxin but not in SIPK- and WIPKsilenced leaves (Fig. 5C), indicating that SIPK and WIPK actually participate in ET production. Silenced leaves were treated with AAL toxin in the presence or absence of ET at 10 $\mu \mathrm{g} / \mathrm{ml}$ (Fig. 5C and D). ACD was not observed and ion leakage was significantly suppressed 3 days after treatments regardless of the ET presence, indicating that SIPK and WIPK have a role in signaling pathways in addition to ET production during ACD.

\section{Tobacco EIN3-like genes also participate in ACD.}

We showed that MAPK cascade and EIN2 participate in ACD (Figs. 2 to 5). Ethylene insensitive 3 (EIN3) and ethylene insensitive-like1 (EIL1), two closely related transcription fac- tors that act downstream of EIN2 (Chao et al. 1997), were isolated as components of ET signaling in Arabidopsis. We further investigated whether the EIN3 ortholog participates in ACD in N. umbratica. In tobacco, tobacco EIN3-like (TEIL) and its related genes have been implicated in ET signaling (Hibi et al. 2007; Kosugi and Ohashi 2000; Rieu et al. 2003). In TEIL knockdown tobacco, wound-, JA- and ACC-induced accumulation of basic $P R$ gene transcripts is significantly suppressed (Hibi et al. 2007), suggesting that TEIL are also involved in ET signaling in tobacco. We used the conserved region of TEIL and NtEIL1-4 for VIGS, because nucleotide acid sequences of TEIL and NtEIL1-4 are highly homologous (Supplementary Fig. S6). We constructed an EIL5-silencing vector, because NtEIL5 nucleotide acid sequences have low homology with TEIL and other NtEIL genes. We confirmed the silencing effects by using qRT-PCR (Fig. 6B). ACD was compromised in TEIL-silenced leaves (Fig. 6A, upper). TEIL-silenced leaves showed reduced disease symptoms caused by $A$. alternata f. sp. lycopersici (Fig. 6A, lower). Toxin-induced ion leakage was reduced in TEIL-silenced leaves (Fig. 6C). These results suggest that TEIL also participate in ACD.

\section{DISCUSSION}

Factors participating in HR cell death have roles in ACD.

In this study, we silenced several genes to access the signaling pathway for ACD. ACD was compromised in $V P E$-silenced leaves (Fig. 2). Arabidopsis contains VPE genes $\alpha V P E, \beta V P E$, $\gamma V P E$, and $\delta V P E$ in the genome (Gruis et al. 2002; Kinoshita et al. 1999). Arabidopsis VPE-null (quadruple) mutant, which lacks all four $V P E$ genes of the genome, abolishes FB1-induced cell death (Kuroyanagi et al. 2005). $N$ gene-mediated HR cell
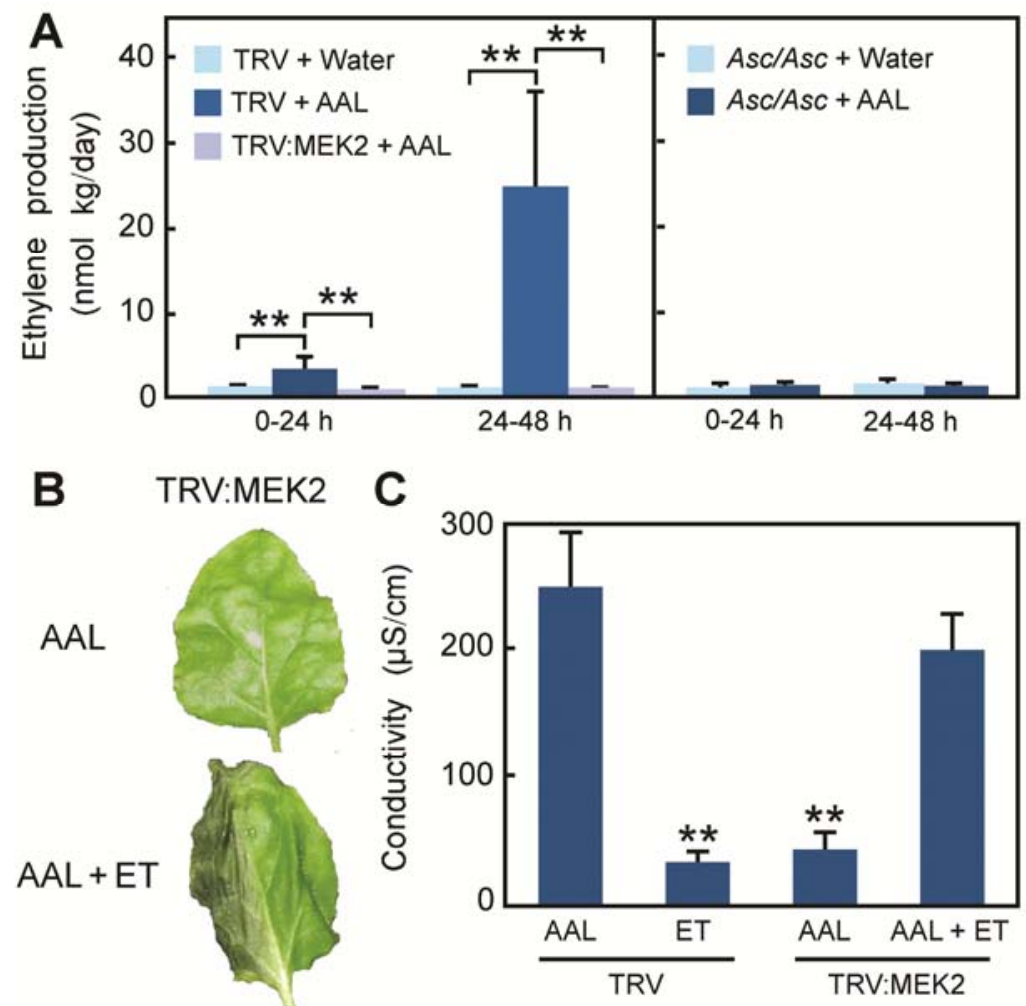

Fig. 4. Participation of MEK2 in ethylene production during AAL toxin-triggered cell death (ACD). A, Measurement of ethylene (ET) production during ACD in MEK2-silenced plants and the Asc/Asc genotype of Nicotiana umbratica. Data are means \pm standard deviations (SD) from at least three independent experiments. Data underwent a Student's $t$ test: ** indicates $P<0.01$. B, MEK2-silenced leaves were treated with AAL toxin in the presence or absence of ET at $10 \mu \mathrm{g} / \mathrm{ml} 3$ days after treatment. C, ACD was quantified by ion leakage from AAL toxin-treated leaves. Data are means \pm SD from at least three independent experiments. Data underwent a Student's $t$ test: ** indicates $P<0.01$ versus AAL toxin treatment in Tobacco rattle virus (TRV) control plants. 
death is suppressed in VPEla- and VPE1b-silenced leaves in $N$. benthamiana (Hatsugai et al. 2004). Whether VPE contribute to PAMP bacterial harpin, fungal Nepland oomycete boehmerin in inducing HR cell death was examined by Zhang and associates (2010). HR was absent in NbVPEla- and $N b V P E 1 a / 1 b$-silenced plants treated with harpin alone in $N$. benthamiana. However, VPE-silenced plants developed a normal HR after boehmerin and Nep1 treatments. Thus, plant VPE-mediated PCD appears to be dependent on the inducer of cell death.

Earlier studies suggested a link between $\mathrm{H}_{2} \mathrm{O}_{2}$ and sphingolipids, two signals that can interplay and regulate plant cell death. Treatment of AAL toxin with Arabidopsis LAG one homologue 2 (loh2) mutant, which is sensitive to AAL toxin, generates $\mathrm{H}_{2} \mathrm{O}_{2}$ (Gechev et al. 2004). Genetic screening of mutagenized loh2 seeds result in isolation of the AAL toxinresistant mutant AAL toxin-resistant 1 (atrl) (Gechev et al. 2008). The atrl mutant shows increased tolerance to ROSgenerating herbicides aminotriazole and paraquat. These studies led us to investigate whether $\mathrm{H}_{2} \mathrm{O}_{2}$ participates in ACD.
However, cell death symptoms showed no differences between TRV control leaves and $R B O H A / B$-silenced leaves at the macroscopic level, even though the conductivity was slightly reduced in $R B O H A / B$-silenced leaves (Fig. 2). One of the most abundant free sphingoid long-chain bases in plants, dihydrosphingosine-induced PCD is not suppressed by DPI in tobacco BY-2 cells (Lachaud et al. 2011). Here, we also showed that DPI treatment did not suppress ACD in N. umbratica leaves. These results suggest that ROS do not participate in perturbations of ceramide metabolism-induced cell death. SIPK induces the expression of the $R B O H$ gene (Asai et al. 2008; Yoshioka et al. 2003), suggesting that AAL toxin-induced MAPK activity is accompanied by ROS production in apoplastic space, because $\mathrm{RBOH}$ proteins localize on the plasma membrane (Kobayashi et al. 2006). On the other hand, ROS generation and PCD induction response to FB1 are not observed in Arabidopsis FB1insensitive mutant FB1 resistant 11-1 (fbrl1-1) (Shi et al. 2007). FBR11-1 encodes long-chain base 1 subunits of serine palmitoyltransferase, which catalyzes the first rate-limiting step of de novo sphingolipid synthesis. Treatments of sphin-
A

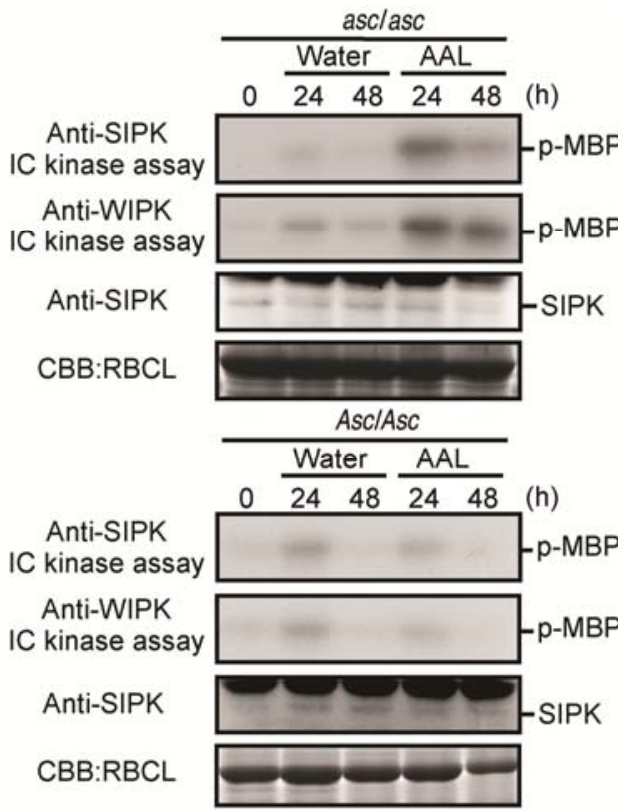

C TRV

AAL

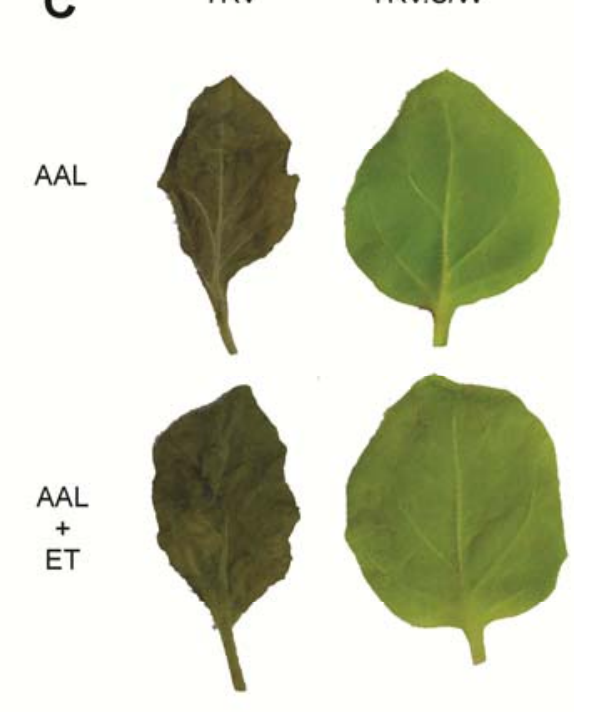

TRV:SN
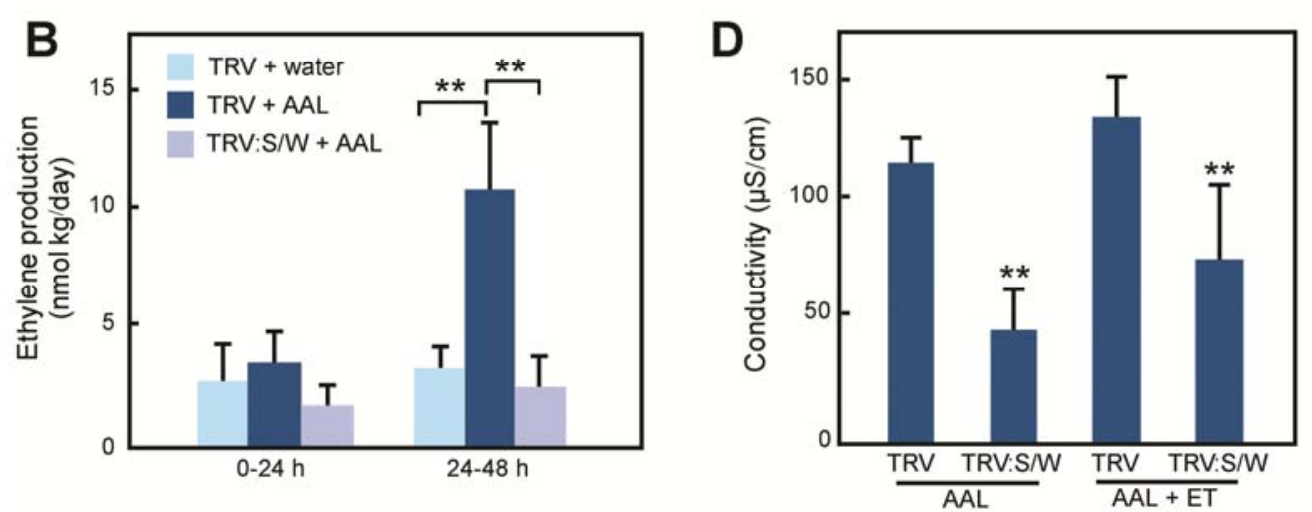

Fig. 5. Ethylene (ET) does not cancel suppression of AAL toxin-triggered cell death (ACD) in SIPK- and WIPK-silenced Nicotiana umbratica leaves. A, Activation of SIPK and WIPK by AAL toxin in the asclasc or the Asc/Asc genotypes of N. umbratica. Kinase activities of extracts were detected by immunocomplex (IC) kinase assay using SIPK- or WIPK-specific antiserum and myelin basic protein (MBP) as a substrate. Immunoblot analyses were done using anti-SIPK antibody. Protein loads were monitored by staining ribulose-1,5-bisphosphate carboxylase large subunit (RBCL) with Coomassie Brilliant Blue (CBB). B, Measurement of ET production during ACD in SIPK- and WIPK (S/W)-silenced plants. Data are means \pm standard deviations (SD) from at least three independent experiments. Data underwent a Student's $t$ test: ** indicates $P<0.01$ versus Tobacco rattle virus (TRV) control plants. C, Effects of silencing S/W on ACD 3 days after treatments. Leaves were treated with AAL toxin in the presence or absence of ET at $10 \mu \mathrm{g} / \mathrm{ml}$. D, ACD was quantified by ion leakage from AAL toxin-treated leaves. Data are means \pm SD from at least three independent experiments. Data underwent a Student's $t$ test: $* *$ indicates $P<0.01$ versus TRV control in each treatment. 
goid bases attenuated in the frb11-1 mutant efficiently induce $\mathrm{O}_{2}^{-}$generation followed by cell death (Shi et al. 2007). We cannot rule out the possibility that other subcellular ROS generators are participated in perturbations of ceramide metabolism-induced cell death.

\section{MAPK activation and ET production resulting}

from ceramide metabolism imbalance by AAL toxin.

Several studies have shown that ceramide metabolism participates in plant PCD. Mutation in accelerated cell death 5 $(A C D 5)$ causes a spontaneous cell death phenotype (Greenberg et al. 2000). ACD5 encodes a ceramide kinase, and recombinant ACD5 proteins have high specificity for ceramides but not for other sphingolipids (Liang et al. 2003). ERH1 encodes inositolphosphorylceramide synthase, which converts ceramide to
A

AAL 3 days
TRV

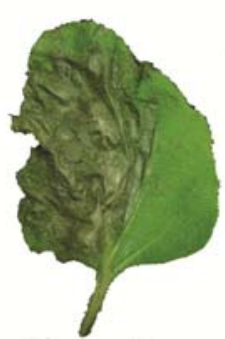

A. alternata

f. sp. lycopersici 6 days

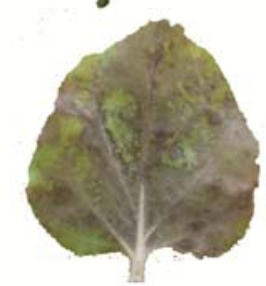

TRV:TEILS TRV:EIL5

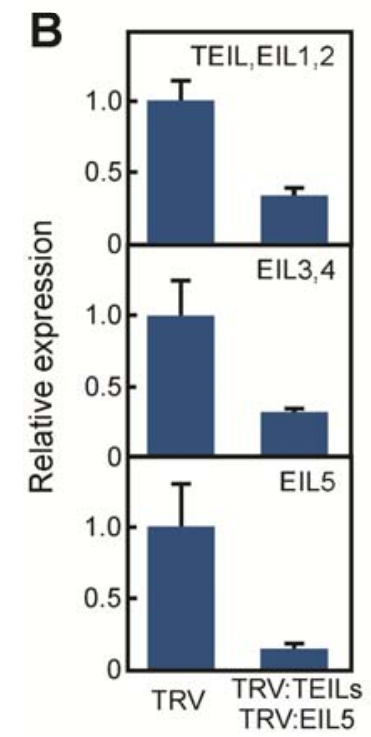

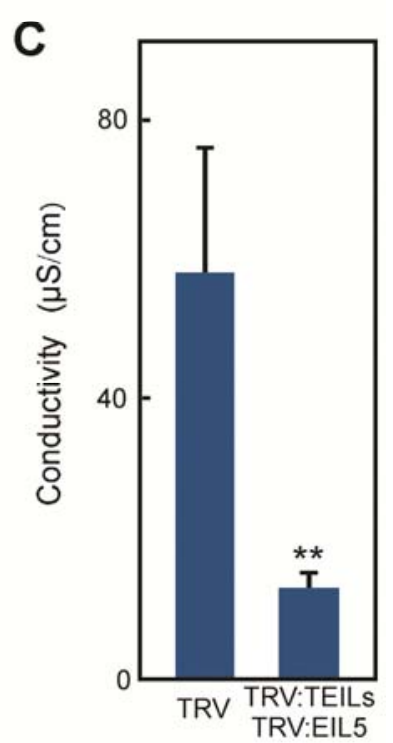

Fig. 6. Silencing tobacco ethylene insensitive 3-like genes (TEIL) compromised AAL toxin-triggered cell death (ACD) and conferred resistance to Alternaria alternata f. sp. lycopersici. A, TEIL-silenced Nicotiana umbratica leaves were treated with AAL toxin or were inoculated with A. alternata f. sp. lycopersici. B, Silencing of target genes was confirmed by using quantitative reverse-transcriptase polymerase chain reaction. $E F-1 \alpha$ was used as an internal standard. Data are means \pm standard deviations (SD) from three experiments. Silencing TEIL included silenced TEIL and EIL1, EIL2, EIL3, EIL4, and EIL5. C, ACD was quantified by ion leakage from AAL toxin-treated leaves. Data are means \pm SD from three experiments. Data underwent a Student's $t$ test: ** indicates $P<0.01$ versus Tobacco rattle virus (TRV) control plants. inositolphosphorylceramide, and loss of function of this gene results in increased transcription of RPW8 and RPW8-mediated HR-like cell death (Wang et al. 2008). Ceramide accumulates in acd5 and erhl mutants (Liang et al. 2003; Wang et al. 2008), suggesting that ceramide participates in plant PCD. Arabidopsis ACD11 encodes a sphingosine transfer protein; a mutation in this gene causes a lesion mimic phenotype characteristic of PCD (Brodersen et al. 2002). However, despite many reports on the participation of ceramide in PCD, how imbalance of ceramide metabolism induces PCD is unknown.

In this study, activation of SIPK and WIPK was detected at 24 and $48 \mathrm{~h}$ after AAL toxin treatment in the asc/asc genotype but not in the Asc/Asc genotype of N. umbratica (Fig. 5A). These results suggest that imbalance of ceramide metabolism activates MAPK (Fig. 7). In mammals, $\mathrm{C}_{2}$ ceramide induces cell death and activates or inhibits MAPK activity in neuronal cells (Arboleda et al. 2010). In rice culture, OsMAPK6 is activated by a sphingolipid elicitor (Lieberherr et al. 2005). MPK6 is activated by FB1 or long-chain base treatment in Arabidopsis thaliana (Saucedo-Garcìa et al. 2011). However, little is known about the participation of ceramide in regulation of MAPK in plants. In this study, we showed that imbalance of ceramide metabolism by AAL toxin induces activation of SIPK and WIPK (Fig. 5A). Therefore, we think these findings provide new insights into regulation of plant PCD.

ET was produced markedly during ACD (Fig. 4A, left). In contrast, ET was not produced in MEK2-, SIPK-, and WIPKsilenced leaves (Figs. 4A, right, and 5B), suggesting that MEK2, SIPK, and WIPK are responsible for ET production during ACD (Fig. 7). In contrast, ET was not produced in the Asc/Asc genotype of $N$. umbratica by AAL toxin treatment

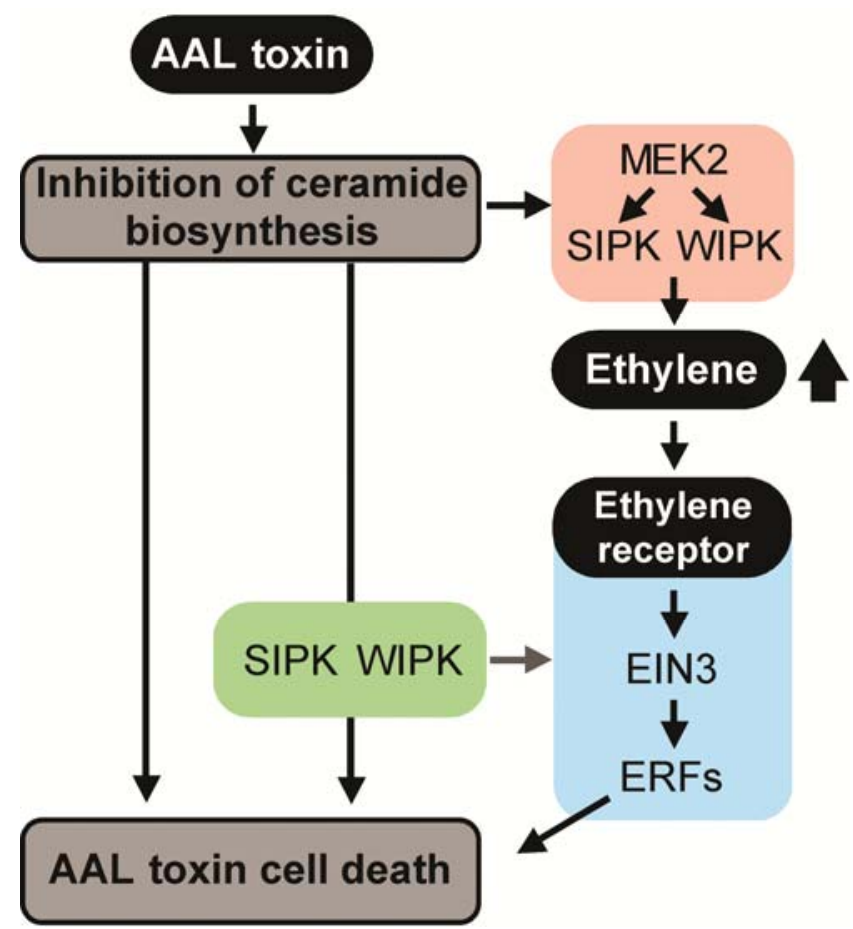

Fig. 7. Scheme of a proposed model for signaling leading to AAL toxintriggered cell death (ACD). AAL toxin inhibits ceramide biosynthesis. The disruption of ceramide biosynthesis may trigger the MEK2-SIPK/WIPK cascade and cell death cascades. Simultaneously, ethylene (ET) production is induced by MEK2-SIPK/WIPK cascade. After perception of ET by its receptor, ethylene insensitive 3 (EIN3) induces ethylene response factors (ERFs), and finally ET responses are initiated. SIPK and WIPK have roles not only in ET production but also in ET signaling or another pathway leading to cell death by AAL toxin. Although ET itself does not induce cell death, ET signaling is required for full induction of ACD. 
(Fig. 4A, right). These results suggest that MAPK activation by imbalance of ceramide metabolism is required for ET production during ACD (Fig. 7).

\section{MEK2, SIPK, and WIPK have distinct roles in ACD.}

ET production is thought to be regulated by activation of the MAPK cascade, because NtMEK2 ${ }^{\mathrm{DD}}$ overexpression induces ET production (Kim et al. 2003). In this study, ET did not increase by AAL toxin treatment in MEK2-silenced plants (Fig. 4A, left). In $M E K 2$-silenced plants, ACD was delayed (Fig. 2) and was recovered by ET treatment (Fig. 4B and C), indicating that $M E K 2$ is responsible for ACD by contributing to ET production (Fig. 7). ACD was compromised in SIPK- and WIPKsilenced leaves (Fig. 5C). Both SIPK and WIPK were activated at 24 and $48 \mathrm{~h}$ after AAL toxin treatment (Fig. 5A, upper), in agreement with ET accumulation (Fig. 4A, left). $M E K 2, S I P K$, and WIPK silencing resulted in reduced ET accumulation induced by AAL toxin (Figs. 4A and 5B), indicating that the MEK2-SIPK/WIPK cascade participates in ET production in $N$. umbratica. Surprisingly, ACD did not recover in SIPK- and $W I P K$-silenced plants in the presence of ET (Fig. 5C), suggesting that SIPK and WIPK may also be responsible for downstream signaling after ET perception by its receptors, as described below.

EIN3 and EIL1 are plant-specific transcription factors that initiate downstream genes for ET responses in Arabidopsis (Alonso et al. 2003; Solano et al. 1998; Yanagisawa et al. 2003). EIN3 interacts with two F-box proteins, EIN3 binding F-box 1 and 2 (EBF1 and EBF2), and is degraded by the $26 \mathrm{~S}$ proteasome in the absence of ET (Guo and Ecker 2003; Potuschak et al. 2003). EIN2 is required for degradation of EBF1 and EBF2 to accumulate EIN3 and EIL1 (An et al. 2010). The regulation of EIN3 stabilization is recently reported to be under the control of bifurcating and antagonistic MAPK cascades (Yoo et al. 2008). MKK9-MPK3/6 phosphorylates EIN3 at its threonine (T) 174 residue, conferring resistance to degradation from the $26 \mathrm{~S}$ proteasome. By contrast, MKK9MPK3/6 independent phosphorylation of the T592 residue promotes degradation of EIN3. We confirmed that conserved docking sites for MAPK and amino acid-corresponding T174 are conserved in TEIL, whereas the amino acid-corresponding T592 was replaced with serine (S) in TEIL (Supplementary Fig. S7). S or T followed by proline (P) (SP or TP) is a minimal consensus motif for MAPK phosphorylation (Sharrocks et al. 2000). The SP motif is conserved in the C-terminal of TEIL. We did not examine whether TEIL are stabilized by the phosphorylation; it is possible that the TEIL are regulated by MAPK, as shown by Arabidopsis EIN3. However, other groups reported that the MKK9-MPK3/6 cascade mainly participates in ET production (Xu et al. 2008). Moreover, MKK9 is not required for ET signal transduction (An et al. 2010). Although how MKK9 acts in ET signaling is arguable, conflicting studies found that MPK3 and MPK6 function either upstream or downstream of ET perception. Orthologs of MEK2, WIPK, and SIPK are MKK4/5, MPK3, and MPK6, respectively (Nakagami et al. 2005) but the MKK9 ortholog of tobacco has not been identified. Our results support the possibility that SIPK and WIPK could have a function not only in ET production but also in ET signaling or another pathway in ACD (Fig. 7).

\section{ET signaling pathway participates in plant PCD.}

We also showed that ACD is compromised in plants treated with MCP, which is an ET receptor blocker, and TEIL-silenced leaves (Figs. 3D and $\mathrm{E}$ and 6). The never ripe mutant of tomato, which affects ET perception, shows less cell death symptom response to AAL toxin than wild-type tomato
(Moore et al. 1999). Co-treatment of asc/asc leaflets with AAL toxin and ET inhibitors markedly reduced cell death symptom (Moussatos et al. 1994). Likewise, ET inhibitors also conferred marked protection against victorin-induced cell death (Navarre and Wolpert 1999). Thus, previous studies support our results that the ET-dependent pathway is required for ACD.

The ET signaling pathway also has roles in HR cell death. ET production increases when tobacco BY-2 cells are treated with INF1 proteins produced by Phytophthora infestans or Pseudomonas syringae attack (Schenke et al. 2005), indicating the possibility that ET has a role in inducing INF1-induced cell death. Various results show that ET biosynthesis, ET signaling, or both participate in regulating HR cell death. For instance, onset of HR-like cell death in tobacco infected with Tobacco mosaic virus (TMV) (Kim et al. 2003), tomato infected with Cladosporium fulvum (Hammond-Kosack et al. 1996), and rice infected with Magnaporthe grisea (Iwai et al. 2006) are accompanied by a large burst of ET production. Tobacco treated with inhibitors of ET biosynthesis or ET perception antagonists show markedly suppressed TMV-induced HR-like cell death and expansion of the virus (Ohtsubo et al. 1999). ET-dependent signaling pathways are required for accelerating HR-like cell death induced by AtMKK5, an ortholog of MEK2, in Arabidopsis (Liu et al. 2008). These data show that ET also participates in HR or HR-like cell death. Investigation of AAL toxin signaling pathways will provide new knowledge about components of plant PCD.

\section{MATERIALS AND METHODS}

\section{Plant growth condition.}

$N$. umbratica plants were grown in environmentally controlled growth cabinets under a 16-h photoperiod and an 8-h dark period at $23^{\circ} \mathrm{C}$. The asc/asc and Asc/Asc genotype of $N$. umbratica were used for bioassays.

\section{Fungal materials.}

Strain EGS39-128 of Alternaria alternata f. sp. lycopersici was used. The strain was routinely maintained on potato dextrose agar (50\% potato stock, $2 \%$ sucrose, and $2 \%$ agar). The A. alternata f. sp. lycopersici isolates were grown for 7 days on oatmeal plates (5\% oatmeal, $2 \%$ sucrose, and $2 \%$ agar) at $25^{\circ} \mathrm{C}$. The aerial mycelium was removed, and then the plates were incubated under continuous black light for profuse sporulation. EGS39-128 was used for a pathogenicity assay by spray inoculation of conidial suspension $\left(5 \times 10^{5}\right.$ spores $\left./ \mathrm{ml}\right)$ to N. umbratica leaves. Plants were incubated at $23^{\circ} \mathrm{C}$ in temperate light and maximum humidity. Lesion formation was observed 6 days after inoculation.

\section{VIGS.}

We amplified cDNA fragments of each gene from the $N$. benthamiana cDNA library as template (Yoshioka et al. 2003). We used $N$. benthamiana cDNAs for VIGS in $N$. umbratica. The cDNA fragments of the genes were amplified with the primers listed in Supplementary Table S1 and were ligated into pTRV2 vector described by Liu and associates (2002) or pTV00 vector described by Ratcliff and associates (2001). The constructs contained these inserts and were designated pTRV2: PDS (TRV:PDS), pTRV2:MEK2 (TRV:MEK2), pTRV2:VPE1b (TRV:VPE), pTV00:EIN2 (TRV:EIN2), pTV00:COI1 (TRV: COI1), pTV00:ICS1 (TRV:ICS1), pTV00:EIL (TRV:EIL), and pTV00:EIL5 (TRV:EIL5). pTV00:RBOHA/RBOHB (TRV: RBOHA/B) was described by Kobayashi and associates (2007). pTV00:SIPK/WIPK (TRV:SIPK/WIPK) was described by Tanaka and associates (2009). pTRV2 or pTV00 that con- 
tained no inserts were used as a control. For VIGS assay, pTRV1, pTRV2, pTV00, or pBINTRA6 and its derivatives were introduced into Agrobacterium GV3101 by electroporation (Bio-Rad, Hercules, CA, U.S.A.). A mixture of equal parts of Agrobacterium suspensions of pTRV1 or pBINTRA6 and pTRV2 or pTV00 was inoculated into 3 -week-old $N$. umbratica seedling. The inoculated plants were grown under a 16-h photoperiod and an 8 -h dark period at $23^{\circ} \mathrm{C}$. After an additional 3 to 4 weeks, plants were analyzed by treatment with AAL toxin and inoculation with A. alternata f. sp. lycopersici and were used for Agrobacterium-mediated transient expression.

\section{RT-PCR.}

Total RNA from $N$. umbratica leaves was prepared using TRIzol reagent (Invitrogen, Carlsbad, CA, U.S.A.) according to the manufacturer's procedure. Reverse transcription was done by using ReverTra Ace -a-, and qRT-PCR analysis was done by using the StepOnePlus Real-Time PCR system (Applied Biosystems, Foster City, CA, U.S.A.) with Power SYBR Green PCR Master Mix (Applied Biosystems). EF-1 $\alpha$ was used as a control. The gene-specific primers of each sequence are listed in Supplementary Table S2.

\section{AAL toxin treatment and agroinfiltration of MEK2 ${ }^{\mathrm{DD}}$.}

For AAL toxin treatment, AAL toxin $(1 \mu \mathrm{M})$ was infiltrated into leaves by using a needleless $1-\mathrm{ml}$ syringe. For agroinfiltration of MEK $2^{\mathrm{DD}}$, transient expression of NtMEK2 ${ }^{\mathrm{DD}}$ was done by agroinfiltration, as described by Takabatake and associates (2006).

\section{Inhibition of ET signal transduction.}

To inhibit ET signal transduction, AAL toxin was simultaneously treated with MCP, an ET receptor inhibitor, at $2 \mu \mathrm{g} / \mathrm{ml}$ in a closed clear acrylic box.

\section{ET treatment.}

Plants were treated with ET $10 \mu 1 /$ liter in a closed box. The volume of boxes was 7 liters and the material of the boxes was clear acrylic.

\section{IC kinase assay.}

The IC kinase assay was done using SIPK-specific antiserum, as described by Asai and associates (2008).

\section{Immunoblotting.}

For immunoblotting, the protein extracts $(20 \mu \mathrm{g})$ were separated on a $12 \%$ sodium dodecyl sulfide polyacrylamide gel and were transferred to a nitrocellulose membrane (Schleicher and Schuell, Keene, NH, U.S.A.). After blocking in Tris-buffered saline with Tween (TBS-T) (50 mM Tris-HCl [pH 7.5], 150 $\mathrm{mM} \mathrm{NaCl}$, and $0.05 \%$ Tween 20 ) with $5 \%$ nonfat dry milk overnight at $4{ }^{\circ} \mathrm{C}$, the membranes were incubated with monoclonal anti-SIPK antibody diluted with TBS-T at room temperature for $1 \mathrm{~h}$. After washing with TBS-T, the membranes were incubated with horseradish peroxidase-conjugated anti-mouse immunoglobulin antibody (Amersham) diluted with TBS-T for $1 \mathrm{~h}$ at room temperature. The antibody-antigen complex was detected using the SuperSignal West Dura Extended Duration Substrate (Thermo Fisher Scientific, Waltham, MA, U.S.A.) and the Light-Capture system (ATTO, Tokyo) and then quantified using the CS analyzer program (ATTO).

\section{Quantitation of ET biosynthesis rates.}

ET production rates were determined by using gas chromatography (GC). Leaves were detached from plants after treatment with AAL toxin and were placed in a 50-ml flask. The flask was sealed with a rubber plunger. After $24 \mathrm{~h}$ of incuba- tion and an additional $24 \mathrm{~h}$ of incubation, a 1-ml gas sample of the air in the flask was collected by using a syringe and was injected into the column. ET was quantified by using a gas chromatograph equipped with a flame thermionic detector (GL Sciences, Tokyo) and NEUTRA BOND-1 (GL Sciences) column. $\mathrm{GC}$ was done at $50^{\circ} \mathrm{C}$ oven temperature, $120^{\circ} \mathrm{C}$ injection, and at detector temperatures using $\mathrm{N}_{2}$ as the carrier gas.

\section{Measurements of cell death.}

Cell death was quantified by measuring ion leakage 3 days after AAL-toxin treatment as describe by Asai and associates (2010). For a conductivity test, five leaf discs (5 or $8 \mathrm{~mm}$ in diameter) were obtained from treated leaves and were immersed in $10 \mathrm{ml}$ of ultrapure water for $4 \mathrm{~h}$ at room temperature with gentle shaking. The conductivity of the solution was measured by using a pH/COND METER D-54 (Horiba, Kyoto, Japan).

\section{Data and statistical analysis.}

At least three repetitions with individual biological sample sets were used for the statistical treatment of the data. The data are expressed as mean values; error bars indicate the standard error. To evaluate the significance of differences of data, data underwent a Student's $t$ test

\section{ACKNOWLEDGMENTS}

We thank S. P. Dinesh-Kumar for the pTRV vector; D. C. Baulcombe for the pTV00 vector; Y. Ohashi and I. Mitsuhara for the NtMEK2 ${ }^{\mathrm{DD}}$ clone; the Leaf Tobacco Research Center, Japan Tobacco, for N. umbratica seeds; and members of the Radioisotope Research Center, Nagoya University, for technical assistance. This work was supported by a Grant-in-Aid for Scientific Research (B) (20380028, 23380025) from the Japan Society of the Promotion of Science and Grant-in-Aid for Japan Society for the Promotion of Science Fellows (10J05393). Conception and design or analysis and interpretation of data was by H. Yoshioka. Drafting the article or revising it critically for important intellectual content was by K. Mase and $\mathrm{H}$. Yoshioka. Final approval of the version to be published was by $\mathrm{K}$. Mase, T. Mizuno, N. Ishihama, T. Fujii, H. Mori, M. Kodama, and H. Yoshioka.

\section{LITERATURE CITED}

Adams, D. O., and Yang, S. F. 1979. Ethylene biosynthesis: Identification of 1-aminocyclopropane-1-carboxylic acid as an intermediate in the conversion of methionine to ethylene. Proc. Natl. Acad. Sci. U.S.A. 76:170-174.

Akamatsu, H., Itoh, Y., Kodama, M., Otani, H., and Kohmoto, K. 1997. AAL toxin-deficient mutants of Alternaria alternata tomato pathotype by restriction enzyme-mediated integration. Phytopathology 87:967972.

Alonso, J. M., Hirayama, T., Roman, G., Nourizadeh, S., and Ecker, J. R. 1999. EIN2, a bifunctional transducer of ethylene and stress responses in Arabidopsis. Science 284:2148-2152.

Alonso, J. M., Stepanova, A. N., Solano, R., Wisman, E., Ferrari, S., Ausubel, F. M., and Ecker, J. R. 2003. Five components of the ethyleneresponse pathway identified in a screen for weak ethylene-insensitive mutants in Arabidopsis. Proc. Natl. Acad. Sci. U.S.A. 100:2992-2997.

An, F., Zhao, Q., Ji, Y., Li, W., Jiang, Z., Yu, X., Zhang, C., Han, Y., He, W., Liu, Y., Zhang, S., Ecker, J. R., and Guo, H. 2010. Ethyleneinduced stabilization of ETHYLENE INSENSITIVE3 and EIN3LIKE1 is mediated by proteasomal degradation of EIN3 binding F-box 1 and 2 that requires EIN2 in Arabidopsis. Plant Cell 22:2384-2401.

Arboleda, G., Cárdenas, Y., Rodráguez, Y., Morales, L. C., Matheus, L., and Arboleda, H. 2010. Differential regulation of AKT, MAPK and GSK3 $\beta$ during $\mathrm{C}_{2}$-ceramide-induced neuronal death. Neurotoxicology 31:687-693.

Asai, S., and Yoshioka, H. 2009. Nitric oxide as a partner of reactive oxygen species participates in disease resistance to nectrotophic pathogen Botrytis cinerea in Nicotiana benthamiana. Mol. Plant-Microbe Interact. 22:619-629.

Asai, S., Ohta, K., and Yoshioka, H. 2008. MAPK signaling regulates nitric oxide and NADPH oxidase-dependent oxidative bursts in Nicotiana benthamiana. Plant Cell 20:1390-1406.

Asai, S., Mase, K., and Yoshioka, H. 2010. A key enzyme for flavin syn- 
thesis is required for nitric oxide and reactive oxygen species production in disease resistance. Plant J. 62:911-924.

Asai, T., Stone, J. M., Heard, J. E., Kovtun, Y., Yorgey, P., Sheen, J., and Ausubel, F. M. 2000. Fumonisin B1-induced cell death in Arabidopsis protoplasts requires jasmonate-, ethylene-, and salicylate-dependent signaling pathways. Plant Cell 12:1823-1835.

Bailey, B. A., Dean, J. F. D., and Anderson, J. D. 1990. An ethylene biosynthesis-inducing endoxylanase elicits electrolyte leakage and necrosis in Nicotiana tabacum cv. Xanthi leaves. Plant Physiol. 94:1849-1854.

Brandwagt, B. F., Mesbah, L. A., Takken, F. L. W., Laurent, P. L., Kneppers, T. J. A., Hille, J., and Nijkamp, H. J. J. 2000. A longevity assurance gene homolog of tomato mediates resistance to Alternaria alternata f. sp. lycopersici toxins and fumonisin B1. Proc. Natl. Acad. Sci. U.S.A. 97:4961-4966.

Brandwagt, B. F., Kneppers, T. J. A., Van der Weerden, G. M., Nijkamp, H. J. J., and Hille, J. 2001. Most AAL toxin-sensitive Nicotiana species are resistant to the tomato fungal pathogen Alternaria alternata f. $\mathrm{sp}$. lycopersici. Mol. Plant-Microbe Interact. 14:460-470.

Brodersen, P., Petersen, M., Pike, H. M., Olszak, B., Skov, S., Odum, N., Jorgensen, L. B., Brown, R. E., and Mundy, J. 2002. Knockout of Arabidopsis ACCELERATED-CELL-DEATH11 encoding a sphingosine transfer protein causes activation of programmed cell death and defense. Genes Dev. 16:490-502.

Chao, Q., Rothenberg, M., Solano, R., Roman, G., Terzaghi, W., and Ecker, J. R. 1997. Activation of the ethylene gas response pathway in Arabidopsis by the nuclear protein ETHYLENE-INSENSITIVE3 and related proteins. Cell 89:1133-1144.

Desjardins, A, E., and Plattner, R. D. 2000. Fumonisin B1-nonproducing strains of Fusarium verticillioides cause maize (Zea mays) ear infection and ear rot. J. Agric. Food Chem. 48:5773-5780.

Egusa, M., Akamatsu, H., Tsuge, T., Otani, H., and Kodama, M. 2009. Induced resistance in tomato plants to the toxin-dependent necrotrophic pathogen Alternaria alternata. Physiol. Mol. Plant Pathol. 73:67-77.

Ekengren, S. K., Liu, Y., Schiff, M., Dinesh-Kumar, S. P., and Martin, G. B. 2003. Two MAPK cascades, NPR1, and TGA transcription factors play a role in Pto-mediated disease resistance in tomato. Plant $\mathrm{J}$. 36:905-917.

Gechev, T. S., Gadjev, I. Z., and Hille, J. 2004. An extensive microarray analysis of AAL-toxin-induced cell death in Arabidopsis thaliana brings new insights into the complexity of programmed cell death in plants. Cell. Mol. Life Sci. 61:1185-1197.

Gechev, T. S., Ferwerda, M. A., Mehterov, N., Laloi, C., Qureshi, M. K., and Hille, J. 2008. Arabidopsis AAL-toxin-resistant mutant atrl shows enhanced tolerance to programmed cell death induced by reactive oxygen species. Biochem. Biophys. Res. Commun. 375:639-644.

Gilchrist, D. G. 1997. Mycotoxins reveal connections between plants and animals in apoptosis and ceramide signaling. Cell Death Differ. 4:689698

Gilchrist, D. G. 1998. PROGRAMMED CELL DEATH IN PLANT DISEASE: The purpose and promise of cellular suicide. Annu. Rev. Phytopathol. 36:393-414.

Glazebrook, J. 2005. Contrasting mechanisms of defense against biotrophic and necrotrophic pathogens. Annu. Rev. Phytopathol. 43:205227

Gomi, K., Ogawa, D., Katou, S., Kamada, H., Nakajima, N., Saji, H., Soyano, T., Sasabe, M., Machida, Y., Mitsuhara, I., Ohashi, Y., and Seo, S. 2005. A mitogen-activated protein kinase NtMPK4 activated by SIPKK is required for jasmonic acid signaling and involved in ozone tolerance via stomatal movement in tobacco. Plant Cell Physiol. 46:1902-1914.

Greenberg, J. T., and Yao, N. 2004. The role and regulation of programmed cell death in plant-pathogen interactions. Cell. Microbiol. 6:201-211.

Greenberg, J. T., Silverman, F. P., and Liang, H. 2000. Uncoupling salicylic acid-dependent cell death and defense-related responses from disease resistance in the Arabidopsis mutant acd5. Genetics 156:341-350.

Gruis, D. F., Selinger, D. A., Curran, J. M., and Jung, R. 2002. Redundant proteolytic mechanisms process seed storage proteins in the absence of seed-type members of the vacuolar processing enzyme family of cysteine proteases. Plant Cell 14:2863-2882.

Guo, H., and Ecker, J. R. 2003. Plant responses to ethylene gas are mediated by $\mathrm{SCF}^{\mathrm{EBF} 1 / \mathrm{EBF} 2}$-dependent proteolysis of EIN3 transcription factor. Cell 115:667-677.

Hammond-Kosack, K. E., Silverman, P., Raskin, I., and Jones, J. D. G. 1996. Race-specific elicitors of Cladosporium fulvum induce changes in cell morphology and the synthesis of ethylene and salicylic acid in tomato plants carrying the corresponding $C f$ disease resistance gene. Plant Physiol. 110:1381-1394.

Han, L., Li, G.-J., Yang, K.-Y., Mao, G., Wang, R., Liu, Y., and Zhang, S. 2010. Mitogen-activated protein kinase 3 and 6 regulate Botrytis cinerea- induced ethylene production in Arabidopsis. Plant J. 64:114-127.

Hatsugai, N., Kuroyanagi, M., Yamada, K., Meshi, T., Tsuda, S., Kondo, M., Nishimura, M., and Hara-Nishimura, I. 2004. A plant vacuolar protease, VPE, mediates virus-induced hypersensitive cell death. Science 305:855-858

Hatsugai, N., Kuroyanagi, M., Nishimura, M., and Hara-Nishimura, I. 2006. A cellular suicide strategy of plants: Vacuole-mediated cell death. Apoptosis 11:905-911.

Hibi, T., Kosugi, S., Iwai, T., Kawata, M., Seo, S., Mitsuhara, I., and Ohashi, Y. 2007. Involvement of EIN3 homologues in basic PR gene expression and flower development in tobacco plants. J. Exp. Bot. 58:3671-3678.

Ishihama, N., Yamada, R., Yoshioka, M., Katou, S., and Yoshioka, H 2011. Phosphorylation of the Nicotiana benthamiana WRKY8 transcription factor by MAPK functions in the defense response. Plant Cell 23:1153-1170.

Iwai, T., Miyasaka, A., Seo, S., and Ohashi, Y. 2006. Contribution of ethylene biosynthesis for resistance to blast fungus infection in young rice plants. Plant Physiol. 142:1202-1215.

Jones, J. D., and Dangl, J. L. 2006. The plant immune system. Nature 444:323-329.

Kamiyoshihara, Y., Iwata, M., Fukaya, T., Tatsuki, M., and Mori, H. 2010. Turnover of LeACS2, a wound-inducible 1-aminocyclopropane-1-carboxylic acid synthase in tomato, is regulated by phosphorylation/ dephosphorylation. Plant J. 64:140-150.

Kamoun, S., Hamada, W., and Huitema, E. 2003. Agrosuppression: A bioassay for the hypersensitive response suited to high-throughput screening. Mol. Plant-Microbe Interact. 16:7-13.

Kende, H. 1993. Ethylene biosynthesis. Annu. Rev. Plant Physiol. Plant Mol. Biol. 44:283-307.

Kim, C. Y., Liu, Y., Thorne, E. T., Yang, H., Fukushige, H., Gassmann, W., Hildebrand, D., Sharp, R. E., and Zhang, S. 2003. Activation of a stressresponsive mitogen-activated protein kinase cascade induces the biosynthesis of ethylene in plants. Plant Cell 15:2707-2718.

Kinoshita, T., Yamada, K., Hiraiwa, N., Kondo, M., Nishimura, M., and Hara-Nishimura, I. 1999. Vacuolar processing enzyme is up-regulated in the lyticvacuoles of vegetative tissues during senescence and under various stressed conditions. Plant J. 19:43-53.

Kobayashi, M., Kawakita, K., Maeshima, M., Doke, N., and Yoshioka, H. 2006. Subcellular localization of Strboh proteins and NADPH-dependent $\mathrm{O}_{2}^{-}$-generating activity in potato tuber tissues. J. Exp. Bot. 57:13731379.

Kobayashi, M., Ohura, I., Kawakita, K., Yokota, N., Fujiwara, M., Shimamoto, K., Doke, N., and Yoshioka, H. 2007. Calcium-dependent protein kinases regulate the production of reactive oxygen species by potato NADPH oxidase. Plant Cell 19:1065-1080.

Kosugi, S., and Ohashi, Y. 2000. Cloning and DNA-binding properties of a tobacco Ethylene-Insensitive3 (EIN3) homolog. Nucleic Acids Res. 15:960-967.

Kuroyanagi, M., Yamada, K., Hatsugai, N., Kondo, M., Nishimura, M and Hara-Nishimura, I. 2005. Vacuolar processing enzyme is essential for mycotox-ininduced cell death in Arabidopsis thaliana. J. Biol. Chem. 280:32914-32920

Lachaud, C., Da Silva, D., Amelot, N., Béziat, C., Briére, C., Cotelle, V., Graziana, A., Grat, S., Mazarsa, C., and Thuleau, P. 2011. Dihydrosphingosine-induced programmed cell death in tobacco BY-2 cells is independent of $\mathrm{H}_{2} \mathrm{O}_{2}$ production. Mol. Plant 4:310-318.

Lee, S.-W., Han, S.-W., Sririyanum, M., Park, C.-J., Seo, Y.-S., and Ronald, P. C. 2009. Type I-secreted, sulfated peptide triggers XA21mediated innate immunity. Science 326:850-853.

Levine, A., Pennell, R. I., Alvarez, M. E., Palmer, R., and Lamb, C. 1996. Calcium-mediated apoptosis in a plant hypersensitive disease resistance response. Curr. Biol. 6:427-437.

Liang, H., Yao, N., Song, J. T., Luo, S., Lu, H., and Greenberg, J. T. 2003. Ceramides modulate programmed cell death in plants. Genes Dev. 17:2636-2641.

Lieberherr, D., Thao, N. P., Nakashima, A., Umemura, K., Kawasaki, T., and Shimamoto, K. 2005. A sphingolipid elicitor-inducible mitogenactivated protein kinase is regulated by the small GTPase OsRac1 and heterotrimeric G-Protein in rice. Plant Physiol. 138:1644-1652.

Lincoln, J. E., Richael, C., Overduin, B., Smith, K., Bostock, R., and Gilchrist, D. G. 2002. Expression of the antiapoptotic baculovirus p35 gene in tomato blocks programmed cell death and provides broad-spectrum resistance to disease. Proc. Natl. Acad. Sci. U.S.A. 99:1521715221.

Liu, H., Wang, Y., Xu, J., Su, T., Liu, G., and Ren, D. 2008. Ethylene signaling is required for the acceleration of cell death induced by the activation of AtMEK5 in Arabidopsis. Cell Res. 18:1-11.

Liu, Y., and Zhang, S. 2004. Phosphorylation of 1-aminocyclopropane-1carboxylic acid synthase by MPK6, a stress-responsive mitogen-acti- 
vated protein kinase, induces ethylene biosynthesis in Arabidopsis. Plant Cell 16:3386-3399.

Liu, Y., Schiff, M., and Dinesh-Kumar, S. P. 2002. Virus-induced gene silencing in tomato. Plant J. 31:777-786.

Lorang, J. M., Sweat, T. A., and Wolpert, T. J. 2007. Plant disease susceptibility conferred by a "resistance" gene. Proc. Natl. Acad. Sci. U.S.A. 104:14861-14866.

Love, A. J., Milner, J. J., and Sadanandom, A. 2008. Timing is everything: Regulatory overlap in plant cell death. Trends Plant Sci. 13:589-595.

Markham, J. E., and Hille, J. 2001. Host-selective toxins as agents of cell death in plant-fungus interactions. Mol. Plant Pathol. 2:229-239.

Moffett, P. 2009. Mechanisms of recognition in dominant $R$ gene mediated resistance. Adv. Virus Res. 75:1-33.

Moore, T., Martineau, B., Bostock, R. M., Lincoln, J. E., and Gilchrist, D. G. 1999. Molecular and genetic characterization of ethylene involvement in mycotoxin-induced plant cell death. Physiol. Mol. Plant Pathol. 54:73-85.

Moussatos, V. V., Yang, S. F., Ward, B., and Gilchrist, D. G. 1994. AALtoxin induced physiological changes in Lycopersicon esculentum Mill: Roles for ethylene and pyrimidine intermediates in necrosis. Physiol. Mol. Plant Pathol. 44:455-468.

Nakagami, H., Pitzschke, A., and Hirt, H. 2005. Emerging MAP kinase pathways in plant stress signaling. Trends Plant Sci. 10:339-346.

Navarre, D. A., and Wolpert, T. J. 1999. Victorin induction of an apoptotic/senescence-like response in oats. Plant Cell 11:237-249.

Ohtsubo, N., Mitsuhara, I., Koga, M., Seo, S., and Ohashi, Y. 1999. Ethylene promotes the necrotic lesion formation and basic $P R$ gene expression in TMV-infected tobacco. Plant Cell Physiol. 40:808-817.

Potuschak, T., Lechner, E., Parmentier, Y., Yanagisawa, S., Grava, S., Koncz, C., and Genschik, P. 2003. EIN3-dependent regulation of plant ethylene hormone signaling by two Arabidopsis F box proteins: EBF1 and EBF2. Cell 115:679-689.

Ratcliff, F., Martin-Hernandez, A. M., and Baulcombe, D. C. 2001. Tobacco rattle virus as a vector for analysis of gene function by silencing. Plant J. 25:237-245

Rieu, I., Mariani, C., and Weterings, K. 2003. Expression analysis of five tobacco EIN3 family members in relation to tissue-specific ethylene responses. J. Exp. Bot. 54:2239-2244.

Sasabe, M., Takeuchi, K., Kamoun, S., Ichinose, Y., Govers, F., Toyoda, K., Shiraishi, T., and Yamada, T. 2000. Independent pathways leading to apoptotic cell death, oxidative burst and defense gene expression in response to elicitin in tobacco cell suspension culture. Eur. J. Biochem. 267:5005-5013.

Saucedo-García, M., Guevara-García, A., González-Solís, A., Cruz-García F., Vázquez-Santana, S., Markham, J. E., Lozano-Rosas, M. G., Dietrich, C. R., Ramos-Vega, M., Cahoon, E. B., and Gavilanes-Ruíz, M. 2011. MPK6, sphinganine and the $L C B 2 a$ gene from serine palmitoyltransferase are required in the signaling pathway that mediates cell death induced by long chain bases in Arabidopsis. New Phytol. 191:943-957.

Schenke, D., Naito, K., Toyoda, K., Inagaki, Y., Shiraishi, T., and Ichinose, Y. 2005. Regulation of elicitin-induced ethylene production in suspension cultured tobacco BY-2 cells. J. Gen. Plant. Pathol. 71:273-279.

Sharrocks, A. D., Yang, S. H., and Galanis, A. 2000. Docking domains and substrate-specificity determination for MAP kinases. Trends Biochem. Sci. 25:448-453.

Shi, L., Jacek, J., Mu, J., Dong, H., Teng, C., Zhang, J., Yang, X., Tomishige, N., Hanada, K., Hannun, Y. A., and Zuo, J. 2007. Involvement of sphingoid bases in mediating reactive oxygen intermediate production and programmed cell death in Arabidopsis. Cell Res. 17:1030-1040.

Solano, R., Stepanova, A., Chao, Q., and Ecker, J. R. 1998. Nuclear events in ethylene signaling: A transcriptional cascade mediated by ETHYLENE-INSENSITIVE3 and ETHYLENE-RESPONSE-FACTOR1. Genes Dev. 12:3703-3714.

Stone, J. M., Heard, J. E., Asai, T., and Ausubel, F. M. 2000. Simulation of fungal-mediated cell death by fumonisin B1 and selection of fumonisin B1-resistant (fbr) Arabidopsis mutants. Plant Cell 12:1811-1822.

Tada, Y., Hata, S., Takata, Y., Nakayashiki, H., Tosa, Y., and Mayama, S.
2001. Induction and signaling of an apoptotic response typified by DNA laddering in the defense response of oats to infection and elicitors. Mol. Plant-Microbe Interact.14:477-486.

Taha, T. A., Mullen, T. D., and Obeid, L. M. 2006. A house divided: Ceramide, sphingosine, and sphingosine-1-phosphate in programmed cell death. Biochim. Biophys. Acta 1758:2027-2036.

Takabatake, R., Seo, S., Mitsuhara, I., Tsuda, S., and Ohashi, Y. 2006. Accumulation of the two transcripts of the $N$ gene, conferring resistance to tobacco mosaic virus, is probably important for $N$ gene-dependent hypersensitive cell death. Plant Cell Physiol. 47:254-261.

Takahashi, Y., Nasir, K. H., Ito, A., Kanzaki, H., Matsumura, H., Saitoh, H., Fujisawa, S., Kamoun, S., and Terauchi, R. 2007. A high-throughput screen of cell-death-inducing factors in Nicotiana benthamiana identifies a novel MAPKK that mediates INF1-induced cell death signaling and non-host resistance to Pseudomonas cichorii. Plant $\mathrm{J}$. 49:1030-1040.

Tanaka, S., Ishihama, N., Yoshioka, H., Huser, A., O’Connell, R., Tsuji, G., Tsuge, S., and Kubo, Y. 2009. The Colletotrichum orbiculare ssd1 mutant enhances Nicotiana benthamiana basal resistance by activating a mitogen-activated protein kinase pathway. Plant Cell 21:2517-2526.

Tsuda, K., Sato, M., Stoddard, T., Glazebrook, J., and Katagiri, F. 2009. Network properties of robust immunity in plants. PLoS Genet. 5:e1000772.

Walton, J. D. 1996. Host-selective toxins: Agents of compatibility. Plant Cell 8:1723-1733.

Wang, H., Li, J., Bostock, R. M., and Gilchrist, D. G. 1996. Apoptosis: A functional paradigm for programmed plant cell death induced by a hostselective phytotoxin and invoked during development. Plant Cell 8:375391.

Wang, W., Yang, X., Tangchaiburana, S., Ndeh, R., Markham, J. E., Tsegaye, Y., Dunn, T. M., Wang, G.-L., Bellizzi, M., Parsons, J. F., Morrissey, D., Bravo, J. E., Lynch, D. V., and Xiao, S. 2008. An inositolphosphorylceramide synthase is involved in regulation of plant programmed cell death associated with defense in Arabidopsis. Plant Cell 20:3163-3179.

Watkins, C. B. 2006. The use of 1-methylcyclopropene (1-MCP) on fruits and vegetables. Biotechnol. Adv. 4:389-409.

Wildermuth, M. C., Dewdney, J., Wu, G., and Ausubel, F. M. 2001. Isochorismate synthase is required to synthesize salicylic acid for plant defence. Nature 414:567-571.

Wolpert, T. J., Macko, V., Acklin, W., Jaun, B., Seibl, J., Meili, J., and Arigoni, D. 1985. Structure of victorin C, the major host-selective toxin from Cochliobolus victoriae. Experientia 41:1524-1529.

Xie, D.-X., Feys, B. F., James, S., Nieto-Rostro, M., and Turner, J. G 1998. COI1: An Arabidopsis gene required for jasmonate-regulated defense and fertility. Science 280:1091-1094

Xu, J., Li, Y., Wang, Y., Liu, H., Lei, L., Yang, H., Liu, G., and Ren, D. 2008. Activation of MAPK kinase 9 induces ethylene and camalexin biosynthesis and enhances sensitivity to salt stress in Arabidopsis. J. Biol. Chem. 283:26996-27006.

Yanagisawa, S., Yoo, S.-D., and Sheen, J. 2003. Differential regulation of EIN3 stability by glucose and ethylene signalling in plants. Nature 425:521-525

Yang, K.-Y., Liu, Y., and Zhang, S. 2001. Activation of a mitogen-activated protein kinase pathway is involved in disease resistance in tobacco. Proc. Natl. Acad. Sci. U.S.A. 98:741-746.

Yoo, S.-D., Cho, Y.-H., Tena, G., Xiong, Y., and Sheen, J. 2008. Dual control of nuclear EIN3 by bifurcate MAPK cascades in $\mathrm{C}_{2} \mathrm{H}_{4}$ signalling. Nature 451:789-796.

Yoshioka, H., Numata, N., Nakajima, K., Katou, S., Kawakita, K., Rowland, O., Jones, J. D. G., and Doke, N. 2003. Nicotiana benthamiana gp91 phox homologs $N$ brbohA and $N$ brbohB participate in $\mathrm{H}_{2} \mathrm{O}_{2}$ accumulation and resistance to Phytophthora infestans. Plant Cell 15:706-718.

Zhang, H., Dong, S., Wang, M., Wang, W., Song, W., Dou, X., Zheng, X., and Zhang, Z. 2010. The role of vacuolar processing enzyme (VPE) from Nicotiana benthamiana in the elicitor-triggered hypersensitive response and stomatal closure. J. Exp. Bot. 61:3799-3812. 